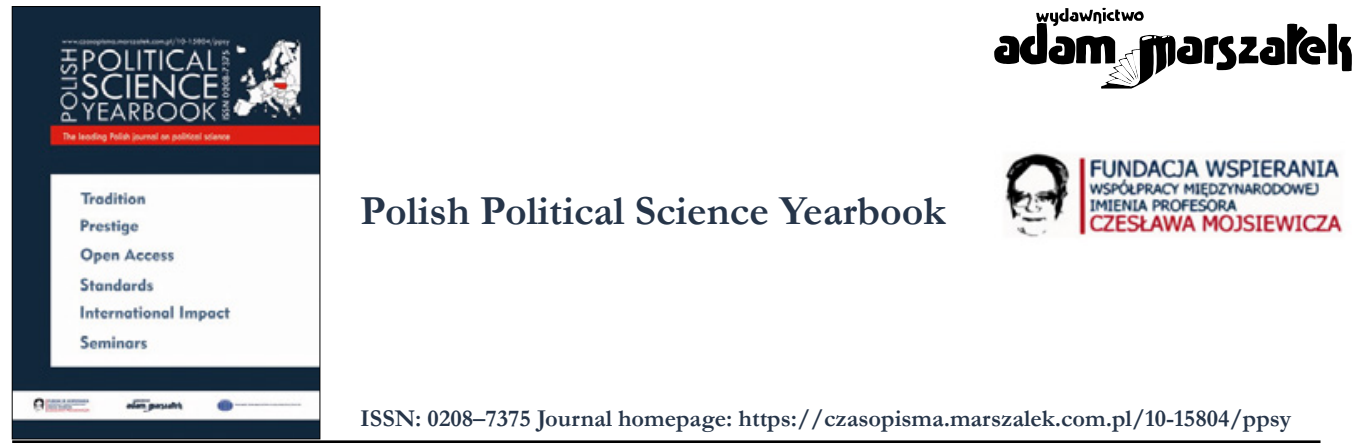

\title{
Humanity-Organization-Technology in View of Industry 4.0 / Society 5.0
}

\section{Andrzej Kiepas}

ORCID: 0000-0001-5279-5288

To cite this article please include the following information:

- Journal title: Polish Political Science Yearbook

- Volume number: 50

- Year of publication: 2021

- Published ahead-of-print

Example styles:

[APA Style]: Kiepas, A. (2021). Humanity-Organization-Technology in View of Industry 4.0 / Society 5.0. Polish Political Science Yearbook, 50(issue number), pages. https://doi.org/10.15804/ ppsy202135

[Chicago Style]: Andrzej Kiepas, "Humanity-Organization-Technology in View of Industry 4.0 / Society 5.0" Polish Political Science Yearbook 50, no. [issue number] (2021).

To link to this article: https://doi.org/10.15804/ppsy202135

Published ahead-of-print

\begin{tabular}{ll} 
Final submission: & 11 April 2021 \\
\hline Published online: & 10 July 2021 \\
\hline Printed issue: $\quad$ December 2021 \\
\hline Submit your article to PPSY
\end{tabular}




\title{
Andrzej Kiepas
}

Silesian University of Technology (Poland)

ORCID: 0000-0001-5279-5288

e-mail: Andrzej.Kiepas@polsl.pl

\section{Humanity-Organization-Technology in View of Industry 4.0 / Society 5.0}

\begin{abstract}
The article addresses selected problems related to the perspective on the development of Industry 4.0 and social and cultural changes that accompany this development and lead toward the so-called post-digital society. In the field of industry, the changes concern, among others, the functioning of various organizations, and in the perspective of post-digital society - human beings and their relations with the world of technology. These changes lead to an increase in the role of technological factors, hence the current revival of technological determinism, and this, in turn, has to do with questions regarding human subjectivity. In this context, questions regarding humans also revolve around the need to acknowledge their increasing capabilities and scope of freedom, and on the other hand, their loss of autonomy in relation to the world of technology.
\end{abstract}

Keywords: Industry 4.0, post-digital society, society 5.0, smart organizations, humantechnology relations

At a time of significant and ground-breaking social and cultural changes, there is a growing interest in humans and their relations with the world, as well as a need to answer the traditional question: who is a human being? Time of significant change brings various uncertainties and threats; simultaneously, they reduce the sense of human security and the accompanying sense of belonging. Such changes are currently taking place in the development of Industry 4.0 and social transformations leading toward Society 5.0 (post-digital society), which are related to this development. As well as its accompanying social and cultural effects, Industry 4.0 can only be anticipated due to the preliminary nature of the processes we are dealing with. It is easier to determine directions and tendencies of the processes taking place than to describe specific phenomena. 


\section{Industry 4.0-Society 5.0 (Post-Digital Society) - General Characteristics}

The perspective of Industry 4.0 is also referred to as the fourth industrial revolution, following the ones involving machinery, electricity, and computers (information). The idea of "Industry 4.0" is associated with the idea of "Society 5.0". The idea of "Society 5.0" appeared as a reaction to the concept of "Industry 4.0", broadening its perspective with social and cultural aspects, while the idea of "Industry 4.0 " focuses on the technological, IT, and economic aspects. The term "Society 5.0" refers directly to social and cultural changes accompanying the development of Industry 4.0. The idea of Society 5.0 indicates that we are dealing with the fifth social revolution, which has emerged as a result of the earlier developments - from hunting societies, through agricultural, industrial, and informational societies to super smart society, i.e., Society 5.0. Its main components are robotization, artificial intelligence, the Internet of Things, and Big Data (Granrath, 2017). The concept of "Society 5.0" and the concept of "Industry 4.0" refer to the same technologies that determine their foundations and important factors of change. The post-digital society can generally be understood as a certain hybrid of the analog and digital worlds. The term "post-digital" does not signify that the limits of what is digital have been crossed, but rather a state of specific saturation of the pre-digital world with digital technologies resulting from its progressive digitalization. Consequently, the boundaries between the analog and digital worlds are being obliterated while the former acquires a new kind of functionality ${ }^{1}$."Post-digital" has a similar meaning here as the definition of contemporary culture as a culture of "real virtuality", where what is real has features of virtuality, and what is virtual has features of what is real. As a result, the "real" and the "virtual" are so intertwined that they no longer exist as separate parts of a larger whole, and the boundaries between them are entirely blurred by the "culture of real virtuality" (Castells, 2007, p. 378). Similarly, although only to some extent and in this rather general sense, one can understand what is meant by "post-digital society". One may think that the terms "Society 5.0" and "post-digital society" refer to the same reality and can be used interchangeably.

The direction of changes we are dealing with here are profound, comprehensive, and can concern in general:

a) elimination of people from work processes - robotization and automation of production processes will also lead to changes in the way how economic organizations function; the current challenges we are facing nowadays rather concern changes in and disappearance of particular professions and the formation of new ones, which

1 A car improved with appropriate technologies acquires new types of functionality and becomes an autonomous vehicle. The change here is qualitative and not just purely quantitative, e.g., optimizing certain technological parameters. 
is connected with the need to acquire new competences (Ford, 2016; Banse, Thelen, and Lingner, 2019);

b) changes in the relations between humans and technology (Kehl \& Coenenen, 2016), which are related to the broadly understood subjectivity of humans - in this context, among other things, there are problems that concern, for example, the causative abilities of humans, the scope of their freedom, the conditions and requirements for the responsibility of humans as moral subjects, or changes in their rationality;

c) social and cultural changes - significant changes have already taken place regarding the development of new media and the medialization processes of various areas of the social and cultural world; the developments in Industry 4.0 lead, among other things, to the formation of a post-digital society as a result of progressive digitalization (Berry \& Dieter, 2015).

The areas and directions of changes enumerated here do not include everything that may result from the changes connected with the perspective of Industry 4.0 and Society 5.0. They only indicate the currently discernible directions of changes and various opportunities that may emerge in the future. The perspective of changes toward Industry 4.0 is assessed variously. There are, for example, such unambiguously optimistic positions as J. Rifkin's, who believes that the logic of civilizational development consisted in the pursuit of independence from nature, which was achieved, among other things, through technological development. However, the civilizational progress carried out through the subordination of nature and creating an artificial world took place in the name of the best interests of particular individuals, economic organizations, or states. The fourth industrial revolution is changing this viewpoint significantly in favor of subordinating individual interests to the interests of the community, which is made possible by modern information technologies (Rifkin, 2016, p. 23). These technologies create new opportunities for cooperation and collaboration among people on a global scale; simultaneously, they also allow to control the consequences of these activities to eliminate negative effects and create conditions for a fair distribution of the effects achieved. It results in the emergence of a prosumer society in which newlyestablished technological platforms create conditions for developing a culture of sharing and not just appropriation (Rifkin, 2016, p. 28). The advancement of smart technologies, based on digital technologies, has a variety of applications and can serve, among other things, to monitor the state of the environment as well as to control various devices and processes and, consequently, to shape various forms of cooperation among people. The web-based dependencies result in turning all the actions into collaborations because they are carried out due to interdependencies and relations with others. Thus, technologies related to Industry 4.0 are treated as those that will somehow automatically lead to the formation of optimal relations between the human being and the world and, consequently, among people on a global scale. However, this faith in the possibilities of technology seems to be clearly exaggerated and overly optimistic. One who formulates more diverse assessments of the future is P. Frase, who does indicate the future as a time of potential equality and affluence 
(Frase, 2016, p. 35 et seq.), but he also sees the possibility that hierarchy and scarcity will be formed along with exterminism, which is associated with it (Frase, 2016, p. 103 et seq.). The future as a result of the development of Industry 4.0 seems to be open and simultaneously far from monochromatic.

\section{Toward Smart Organizations}

The development processes of Industry 4.0 are heading toward optimizing the operation of various economic organizations based on the use of information technology and smart technologies. Above all, these include such technological (IT) devices as cloud computing, Big Data, augmented reality, virtual simulations, the Internet of Things, 3D printers, and finally, artificial intelligence and robotization. As a result of the dissemination of these technologies, organizations are to operate so that their activities can be optimized in different levels and areas of their operation, e.g., financial, marketing or production, in the case real-time. Unlike in organizations, where computerization has been applied separately to organizations aiming at Industry 4.0, all the mentioned areas are to function interrelatedly, thus creating a single entity that will optimize itself in real-time.

A broadly understood optimization of the mode of operation in relevant organizations constitutes the basic goal connected with implementing the "Industry 4.0" concept. Achieving such optimization will consequently lead to the real world becoming interspersed with the virtual one. The current state of functioning of a particular organization thus becomes an impermanent state. It is a state of certain potentiality or virtuality that can change and transition to another state under even a single factor. In this respect, there is no need to overcome a certain degree of inertia to cause changes. If one treats an organization as a system, it will be a system that is:

- open - never truly reaching a state of permanent equilibrium; on the contrary, remaining in a state of continuous internal and external imbalance and therefore susceptible to various factors and changes;

- not fully defined and determined - the changes resulting from the disruption of the current state do not cause the recurrence of what has already been there, but the formation of new states; what is to emerge is not entirely and unambiguously predictable and designed, and hence the causal dependencies and determinations that will occur here will often have only a local, not a universal, character.

An intelligent organization will optimize not only its way of functioning as a certain entity, but it will also - through appropriate technologies - optimize its relationship with its environment. With its surroundings as not only the natural environment but also with the social and cultural environment. The development of smart organizations can contribute to the realization of ideas and requirements of sustainable development, which is connected with closing the cycle of matter circulation within the social and economic system. With the use of, e.g., the Internet of Things, what turns out necessary 
and possible is also the implementation of technological and informational solutions as well as the application of new methods of ecological management, which - through appropriate control - should cause acceleration or even enforcement of material substitution and design of systems which do not generate waste. Consequently, the point is to strive for full closure of the cycle by procedural and structural integration of various entities affecting the environment, because then it will be possible to implement sustainable development, which from the ecological perspective can be described as ecologically clean and not burdening the environment. The fourth industrial revolution facilitates it because the revolution consists of the comprehensive use of intelligent technologies to monitor environmental impact and exert proper control over this impact. Moreover, what makes it possible is the precise determination of the quality and quantity of materials that contribute to a given thing, i.e., the appropriate material and energy management. It means unequivocally that the basic conditions are created for a circular economy that will simultaneously function according to the principles of sustainable development. The Internet of Things also provides opportunities here for continuous and essentially publicly available monitoring of the state of the environment, which is directly dependent on the degree of human interference in this environment. Consequently, it may influence the shaping of appropriate relations between humans and the environment according to the principles of sustainable development, which in turn will not be indifferent to the state of this environment (Kiepas, 2017b). The perspective of Industry 4.0 involves the creation, shaping, and expanding a specific infrastructure that constitutes both an artificial and natural environment for various organizations and institutions. This infrastructure will include humans and various products manufactured by them and, as a result, apart from certain elements of the natural world, it will involve their socio-cultural environment. Connected with dependencies built based on possibilities created by appropriate technologies, a smart organization will function as a self-optimizing system subordinated to the criteria of sustainable development, i.e., simultaneously contributing to the proper functioning of the social and cultural environment of such organizations with regard to these criteria.

\section{Changes in Human-Technology Relations}

The direction of anthropological change is revealed in the relations between humans and technology in general. Forced by technological development, these changes do not remain irrelevant to humanity since technology is not an entirely neutral means that humanity, as a subject of the action and making the right choices, can control entirely and make subordinate to itself. In other words, the entanglement of a human being as an intentional subject - acting consciously and with a certain intention - in technology makes it impossible to remain indifferent to it. The use of technology does not allow for indifference, especially since the dissemination and use of technology change humans' social and cultural environment and, as a consequence, is not neutral for them (Lizut, 2014, p. 71 et seq.). 
The shaping of post-digital society leads to significant changes in the relationship between humans and technology. The broader context of these changes is related to problems discussed earlier, among others, concerning the changes in contemporary culture caused by the development and dissemination of new media (Kiepas, 2017a). The development of Industry 4.0 / post-digital society is also associated with further growth of instrumentalization in various areas of human life and activity, which has been ongoing since modernity. The development of information technologies - especially artificial intelligence - creates new possibilities of instrumentalization in these areas and new conditions for various relations between human beings and the world. The question about humans may concern various conditions in which the human subjectivity manifests itself as well as manners of its manifestation; therefore, what may be deemed crucial to determine here, e.g., are the following aspects of the said question:

- the causative capabilities of the human being - these capabilities are currently largely dependent on the technology available in specific conditions; the additional context of the question about these causative capabilities is connected with the fact that contemporary activities are mostly institutionalized, and therefore any activity usually constitutes a collaboration with others, with whom the appropriate causative powers of particular entities are shared (Zacher, 2016);

- in the modern tradition, the right to freedom was emphasized as an essential element of human nature, and thus the autonomy of the will combined with reason defined human subjectivity;

- the axiological (moral) competence - i.e., the ability to evaluate decisions, actions, and their consequences concerning values, including moral values.

The question about the conditions of human subjectivity, both in relation to technology and among people, refers to the intentionality of a human being, i.e., to the intention of the person acting (free will) and their awareness of what is being done by them and what the consequences of actions and decisions taken may be. However, the intentionality of actions remains largely unclear, and its additional entanglement with technology poses further problems here. The fact that technology has gained an intermediary function in actions and decisions is not indifferent to the person acting, e.g., in relation to the effects of their actions or emotional involvement. Trust allows one to act and cooperate but does not eliminate the uncertainty about the intentionality of cooperating entities. Other characteristics of subjectivity, such as competences or skills, seem to be more transparent, controllable, and verifiable in this respect. Trust is never absolute. It always is accompanied by a certain degree of mistrust, and the interaction of people within a certain social and cultural order always is a kind of interplay between trust and mistrust (Luhmann, 2007, p. 124). The same can also be said about the relationship between the human being and technology, all the more so because in the case of the Internet of things or artificial intelligence, while interacting with technology, we have to deal with objects which can also be attributed with appropriate intentionality, not entirely reduced to the usefulness determined by the human being 
(disposability, handiness, etc.). Additionally, through self-confirmation of potential, trust creates conditions for developing subsequent and often new forms of social cooperation (Luhmann, 2007, pp. 123-124). However, the role of trust, which previously existed in the relationship between humans and technology, has been subject to certain changes from the perspective of post-digital society. Trust in technology had hitherto been based on the possibility of subjecting technology to the intentionality of its users. As users of technology, we could impose our intentionality on technology. Even if these possibilities were somehow limited, the relationship between the human being and technology was based on the conviction that our intentionality was important and often decisive. As users of technology, we had a feeling of control over the effects of our actions, although there was never any guarantee of full control over the effects resulting from the use and dissemination of technology. However, given the post-digital society and the ongoing developments in Industry 4.0, the dependence on technology is increasing as technology begins to function in an increasingly autonomous manner. The entanglement of the human being as a subject along with his or her intentionality in relations with technology makes the human being more and more dependent on technology. The intermediary function of technology in our relations to others and the world causes the technologically recognized and determined state of the world - our living and working environment - to define our subjectivity. After all, we no longer live in a world with which we have direct relations, but in a world constructed and formed by specific technologies, and today these are such technologies as artificial intelligence, Big Data, the Internet of Things, etc. Human intentionality as a subject using various types of technology is becoming increasingly dependent on the technology itself. It widens the scope of the trust we are required to place in technology while the scope of our intentionality becomes narrower. The development of these technologies also entails various side effects and unintended, i.e., not in line with the users' intentions or the entities deciding to disseminate it. There are many reasons why unintended consequences (involuntary, extraneous) occur. So, the following ones can be pointed out here as examples: non-neutral character of technology itself, institutional and not only individual character of actions, cumulative and casual character of effects, the web-based character of dependencies and processes. The developments in the post-digital society are also accompanied by the new potential for unintended consequences, such as using different types of algorithms. Technology is not entirely neutral, and this is also confirmed, e.g., by such "soft" technologies as various algorithms, the use of which may have quite significant social and cultural consequences, e.g., as tools of specific exclusion processes (Neil, 2017). In this way, algorithms and models of various sorts become "weapons of math destruction", and their use is not entirely neutral and can lead to various unintended consequences, e.g., in the field of justice (Neil, 2017, p. 126 et seq.). Trust in human-technology relations also gets essentially extorted here by technology because it, together with its capabilities, determines the scope and limits of what we should trust. Trust also opens up certain possibilities for acting, i.e., it is a factor that additionally determines the scope of our freedom. However, at the same time, it happens at the cost of 
giving up this freedom, or part of it, for the sake of submission to technology. The development and dissemination of various types of information technologies means that building up trust is nowadays carried out largely through technologically mediated communication (Internet of Things and new media). As the digitalization processes are progressing, the scope of communication is expanding, which is reflected in the fact that:

- in the case of technologically mediated communication, technology played the intermediary role, i.e., something in the middle between the subjects participating in the process of communication; as an intermediary or a medium, it remained something opaque, in a way undefined, because the process of communication was based on the models derived from the theory of cognition; the process of cognition took place between the subject and the object, while the medium was a kind of "black box", only connecting the subject and the object (Mersch, 2010); the position taken by the Canadian School and especially by M. McLuhan with his famous formula "the medium is message" indicated, however, a kind of non-neutrality of the technological means of communication; this position could be interpreted as an expression of recognition for technological determinism - i.e., a theory assuming that the technology used by a given society for communication constitutes an autonomous factor in the society's social and cultural change - but also as an indication that technology as a medium of communication is not an entirely neutral means; on the one hand, the processes of digitization reduce the importance of technological factor, but on the other hand, they shift the determination to the level of the message itself and, therefore, in relation to the world of new media, it is expressed in a phrase "message is message" (Castells, 2007, p. 377);

- communication carried out between people (P2P, i.e., Peer-to-Peer) additionally overlap with the communication happening between certain technological means (M2M, Machine-to-Machine) which form, e.g., a network of the Internet of Things. The communication between these technological devices proceeds according to certain algorithms. However, the question arises as to what extent the effects of this communication's functioning and the algorithms that form it are controllable and predictable and, on the other hand, what they will turn out to be as a consequence of their overlapping with the communication between people (Miller, 2016, p. 22 ff.).

As a result of digitization processes and the expansion of communication processes, changes are occurring in the relationship between the human being and technology because:

a) the two areas of communication, P2P and M2M, are not entirely separate and independent, but they overlap; the resulting combination cannot be simply added up and, therefore, it may be difficult to predict and control its effects;

b) although M2M communication is digital (algorithmic) in nature, this does not mean that it is fully closed and determined within the framework defined by the 
relevant "input" algorithms; contemporary algorithms remain - at least to some extent - open; this can be exemplified by the case of artificial intelligence that in the course of its implementation can change the initial manner in which it is supposed to "learn" and thus to expand its "learning" capacity.

With the development of new media, i.e., multimedia, there appeared problems - in many different respects - concerning the identity of network communication participants. In the M2M communication processes in their interactions with the $\mathrm{P} 2 \mathrm{P}$ communication, the development of artificial intelligence may create similar or additional problems related to what can be accidentally generated in the M2M area and influence the participants of P2P communication.

At the same time, the indicated changes show how the role of technology gains in importance and how humans become dependent on it. The role of technology in humantechnology relations is, in fact, ambivalent. For example, technology broadens the scope of our freedom by increasing the possibilities of action that would not be possible without it, but this takes place at the cost of human dependence on technology, which consequently limits our freedom. The expansion of people's potential for action is accompanied by an increase in the extent to which technology determines their actions and an increase in the level of their dependence on it. Similar changes to the ones we are dealing with regarding trust can also be observed in relation to responsibility and its new requirements because of Industry 4.0 and post-digital society. Responsibility becomes co-responsibility (Kiepas, 2017a, p. $78 \mathrm{ff}$.), i.e., a responsibility shared among people and between people and technology. In the case of robots, as they will gain an increasing degree of independence (autonomy), humans will have to entrust technology with axiological and moral competences. It was already postulated at one time by I. Assimov, who was discussing "robot ethics". The limitation of the "robot ethics" as postulated by the writer was its unambiguously anthropocentric character. However, with the development of post-digital society, the necessity to equip technology with certain axiological (moral) competences will probably arise (Assimov, 2013; Campa, 2011).

The dynamics of the processes of technological development and the accompanying power of determination and the scope of technological influence mean that, in this relation, it is a technology that seems to increasingly dominate and subordinate humans. Technology is superior to the human being in many respects; its instrumental and cognitive capabilities are greater. The traditional philosophy of technology has already pointed to its anthropological functionality (Kiepas, 2000, p. 11 et seq.). Technology and its development processes were interpreted as an extension, enhancement, and substitution of human organs and their functions, and consequently of the whole human nature (Gehlen, 2001, p. 145 ff.). Humans transferred their instrumental and cognitive competences to technology, though in essence, technology remained a means of supporting human capabilities to a defined extent. In post-digital society, the situation begins to change because, e.g., the development of the Internet of Things, robotization, and artificial intelligence leads to the autonomization of the technological world. Intelligent technologies eliminate humans from professions and 
jobs traditionally performed by the latter. By transferring their competences and capabilities to the world of technology, humans are slowly but increasingly becoming dependent on and subordinate to technology (Grunwald, 2019) and from this perspective appears to be obsolete, antiquated beings ("Antiquiertheit des Menschen") (Yannick, 2019). The development processes of Industry 4.0 / post-digital society lead to various assessments of their significance for humans. On the one hand, they seem to expand the human being's capabilities, but on the other, they also bring about various risks and uncertainties. By interfering with human nature, the development of technology takes on such a liminal character. Therefore, questions arise about the limits of this interference and, in this case, about the possible influence of technology on the sphere of human rationality and emotionality. From this perspective, it seems sensible to ask: "Are we as humans left only with the world of feelings as a genuinely human realm in which we are superior to technology? If this diagnosis were true, wouldn't this be one of the anchor points for why the so-called felt truths currently play such an important role?"2 (Yannick, 2019, p. 77). Artificial intelligence is modeled on human intelligence, and its development is directed toward it becoming the same. Is this possible in the context of the raised question about feelings and emotionality? At the moment, there are all kinds of doubts here. On the other hand, however, and from the perspective of the relationship between humans and technology, we can state that the development and dissemination of new technologies are far from indifferent to humans and have a definite influence on them. By causing certain changes in humans, this influence will result in reciprocal changes in the world of technology. Humans and technology create a world of mutual interaction. In technology, this is how the human being is modeled, and hence their future in the digital world remains open, fraught not only with ambiguity but also with uncertainty. One of the consequences of this mutual interaction between humans and technology is the progressive subjectivization of the human world, which in various areas of its functioning loses objective measures in favor of more uncertain and variable subjective measures. Signs of this subjectivization are manifested in various areas of the human world and can be described as a "no world's land." With the formation of the post-digital reality, we are entering a "land" without any world as we have hitherto known it, without such rationality as we have known it before; and this is an adventure of a special kind, full not only of hope but also many fears. The post-digital society as a "no world's land" consists of, among other things:

- art without aesthetics - art is not that which meets certain aesthetic canons, but that which causes appropriate effects and reactions in its recipients;

- politics without strategy - the mediatization of politics has led to the situation where it is becoming more of a tool for manipulation than a means of creating the

2 "Bleibt uns als Menschen nur noch die Welt der Gefühle als genuin menschlicher Bereich, in dem wir der Technik überlegen sind? Wenn diese Diagnose zuträfe, finde sich hier nicht einer der Ankerpunkte, warum die sogenannten gefühlten Wahrheiten eine derzeit so große Rolle spielen?” 
common good; the effectiveness of action is replaced by the ability to manipulate, and it is not wisdom (knowledge);

- education without knowledge - the Web is a source of knowledge - at least its informational part and while people are being eliminated from the work processes, specialist knowledge will be eliminated from the education processes in favor of general life education; in the past, education was to help one gain competence on how to acquire knowledge and act (live) in this world in the event of insufficient (incomplete) data; today education w the era of Big Data should rather help one gain competence on how to ignore information and how not to assimilate it;

- humans without work - instead of places of permanent work, attempts can be made to create places where people will be able to do "something" if need be;

- economy without money - real money is being replaced by virtual money, and the parity of gold has long ceased to be a measure of a given country's strength;

- science without theory - science is becoming largely dominated by pragmatic approach (grants); in this context, there are also discussed models of science dependent on the processes of digitization such as open science, citizen science, or real labor, which aim to de-professionalize science and lend it new practical values;

- a society without community - contrary to optimists' opinion, the Internet and new media have not become a tool for bringing people together and creating community, but they often become a means of exclusion and creating new tribal, impermanent, and illusory communities at best.

This subjectivization manifests itself in the changes in the measures and criteria of rationality inherent in these areas. Of course, the existing measures and criteria have not yet wholly lost their meaning, but there are signs that these rationalities are eroding.

The post-digital society, along with the emerging "no world's lands" as specific worlds and living environment of a human being, open to him/her previously unknown possibilities, but on the other hand, they also give rise to uncertainty and threats. Although uncertain, to some extent, the future can be known and actualized, all the more so as contemporary technologies provide in this respect previously unknown opportunities. When it comes to the development of Industry 4.0 and the formation of post-digital society, we are dealing with processes that will lead to significant changes in the human condition and the world.

\section{References:}

Assimov, I. (2013). Ja, robot (I, Robot). Rebis.

Banse, G., Thelen, J., and Lingner, S. (2019). Industrie 4.0 zwischen Idee und Realität. Ein Ländervergleich. Trafo Verlag.

Berry, D.M., \& Dieter, M. (Eds.). (2015). Postdigital Aesthetics. Palgrave Macmillan.

Ford, M. (2016). Swit robotów. Czy sztuczna inteligencja pozbawi nas pracy? (Rise of the robots: technology and the threat of a jobless future). Cdp.pl. 
Campa, R. (2011). Kodeksy etyczne robotów; zagadnienie kontroli sprawowanej przez człowieka (Two Roboethics Approaches: The Problem of Human Control). Pomiary-Automatyka-Robotyka, 3, 66-70. Castells, M. (2007). Społeczeństwo sieci (Rise of the network society). PWN.

Frase, P. (2018). Cztery przyszłości. Wizje świata po kapitalizmie (Four Futures: Life After Capitalism). PWN.

Gehlen, A. (2001). W kręgu antropologii i psychologii społecznej (Anthropological and Social Psychological Studies). Czytelnik.

Granrath, L. (2017). Japan's society 5.0: Going beyond industry 4.0. https://www.japanindustrynews. com/2017/08/japans-society-5-0-going-beyond-industry-4-0

Grunwald, A. (2019). Der unterlegene Mensch. Die Zukunft der Menschheit im Zeitalter der Algorithmen. Riva Verlag.

Kehl, Ch., \& Coenen, Ch. (2016). Technologien und Visionen der Mensch-Maschine Entgrenzung. TABArbeitsbericht, 167.

Kiepas, A. (2000). Człowiek wobec dylematów filozofi techniki (Man and the Dilemmas of Philosophy of Technology). Wydawnictwo Gnome.

Kiepas, A. (2017a). Filozofia techniki w dobie nowych mediów (Philosophy of Technology in the Age of New Media). Wydawnictwo Uniwersytetu Śląskiego.

Kiepas, A. (2017b). Zrównoważony rozwój w perspektywie "przemysłu 4.0" (Sustainable Development in the Perspective of "Industry 4.0"). In R.F. Sadowski, \& Z. Łepko (Eds.), Theoria i praxis zrównoważonego rozwoju (Theoria and Praxis of Sustainable Development) (pp. 533-546). Towarzystwo Naukowe Franciszka Salezego.

Lizut, R. (2014). Technika a wartości. Spór o aksjologiczna neutralność artefaktów (Technology and Values. Dispute Over Value-neutrality of Technology). Wydawnictwo Academicon.

Luhmann, N. (2007). Systemy społeczne (Social Systems). Zakład Wydawniczy "Nomos".

Mersch, D. (2010). Teorie mediów (An Introduction to Media Theories). Sic!

Miller, M. (2016). Internet rzeczy. Jak inteligentne telewizory, samochody, domy i miasta zmieniaja świat (The Internet of Things: How Smart TVs, Smart Cars, Smart Homes, and Smart Cities Are Changing the World). PWN.

Neil, C.O., (2007). Broń matematycznej zagłady. Jak algorytmy zwiększają nierówności i zagrażają demokracji (Weapons of Math Destruction: How Big Data Increases Inequality and Threatens Democracy). PWN.

Rifkin, J. (2016). Społeczeństwo zerowych kosztów krańcowych (The Zero Marginal Cost Society: The Internet of Things, the Collaborative Commons, and the Eclipse of Capitalism). Studio Emka.

Zacher, L.W.(Ed.). (2016). Moc sprawcza ludzi i organizacji (The Causal Power of People and Organizations). Poltext.

Yannick, J. (2019). Rezension. Der unterlegene Mensch. Digitalisierung zwischen Hoffen und Bangen. TATuP. Zeitschrift für Technikfolgenabschätzung in Theorie und Praxis, 3, 76-77. 